\title{
Pharmacotherapy in mania and depression
} Heinz Grunze

\author{
Address: Department of Psychiatry LMU Munich, Germany \\ from International Society on Brain and Behaviour: 3rd International Congress on Brain and Behaviour \\ Thessaloniki, Greece. 28 November - 2 December 2007 \\ Published: 17 April 2008 \\ Annals of General Psychiatry 2008, 7(Suppl I):S65 doi:I0.1 I86/I744-859X-7-SI-S65
}

This abstract is available from: http://www.annals-general-psychiatry.com/content/7/SI/S65

(c) 2008 Grunze; licensee BioMed Central Ltd.

Bipolar disorders are characterised by an irregular, partially chaotic pattern of mood swings and, most difficult to treat, mixed states where both symptoms of mania and depression are concurrently present. Thus, individualised treatments, quickly adapting to the prevailing symptomatology, becomes necessary. There is a clear indication for mood stabilisers thus as lithium, valproate, carbamazepine or lamotrigine to improve the long-term course of the illness; however, short-term interventions are often necessary tailored to specific symptoms without provoking other symptoms or worsening the long-term outcome. The use and usefulness of antidepressants in bipolar disorder still remains a matter of ongoing controversy. Concerning efficacy, a metaanalysis [1] and a recent systematic review [2] supports the use of some antidepressants in treating acute bipolar depression. However, recent data of the STEP-BD program also question their true clinical effectiveness [3]. On the manic side, conventional antipsychotics are effective [4], but their tolerability is often poor. With their superior tolerability profile atypical antipsychotics appear to be useful tools in such a symptom orientated treatment. Besides antimanic properties, several atypical antipsychotics have shown efficacy in mixed mania [5], psychotic mania [6] and, especially quetiapine and olanzapine, bipolar depression [7]. In addition, they may be useful in stabilising frequently cycling patients $[8,9]$. In addition, there is increasing evidence for prophylactic efficacy of atypical antipsychotics against break-through mania (aripiprazole [10], risperidone (unpublished)) and both new manic and depressed episodes (olanzapine [11], quetiapine (unpublished). Thus, atypical antipsychotics may emerge as a true alternative to standard treatment with mood stabilizers in combination with antimanic or antidepressant agents.

\section{References}

I. Gijsman HJ, Geddes JR, Rendell JM, Nolen WA, Goodwin GM: Antidepressants for bipolar depression: a systematic review of randomized, controlled trials. Am J Psychiatry 2004, 161(9): 1537-1547.

2. Fountoulakis K, Grunze H, Panagiotidis P, Kaprinis G: Treatment of bipolar depression: an update. Journal of Affective Disorders 2007. Epub ahead of print

3. Sachs GS, Nierenberg AA, Calabrese JR, Marangell LB, Wisniewski SR, Gyulai L, et al:: Effectiveness of adjunctive antidepressant treatment for bipolar depression. N Engl J Med 2007, 356(17): 17II-I722.

4. Cipriani A, Rendell JM, Geddes JR: Haloperidol alone or in combination for acute mania. Cochrane Database Syst Rev 2006, 3: CD004362.: CD004362.

5. Vieta $E:$ The treatment of mixed states and the risk of switching to depression. Eur Psychiatry 2005, 20(2):96-100.

6. Dunner DL: Atypical antipsychotics: efficacy across bipolar disorder subpopulations. J Clin Psychiatry 2005, 66(Suppl 3):20-7. 20-27.

7. Gao K, Gajwani P, Elhaj O, Calabrese JR: Typical and atypical antipsychotics in bipolar depression. J Clin Psychiatry 2005, 66(II): 1376-1385.

8. Vieta E, Calabrese J, Goikolea J, Raines S, Macfadden W: Quetiapine monotherapy in the treatment of patients with bipolar I or II depression and a rapid-cycling disease course: a randomized, double-blind, placebo-controlled study. Bipolar Disord 2007, 9(4):4I3-425.

9. Berk M, Dodd S: Efficacy of atypical antipsychotics in bipolar disorder. Drugs 2005, 65(2):257-269.

10. Keck PE, Calabrese JR, McQuade RD, Carson WH, Carlson BX, Rollin LM, et al.: A Randomized, Double-Blind, Placebo-Controlled 26- Week Trial of Aripiprazole in Recently Manic Patients With Bipolar I Disorder. J Clin Psychiatry 2006, 67(4):626-637.

II. Tohen M, Calabrese JR, Sachs GS, Banov MD, Detke HC, Risser R, et al: Randomized, placebo-controlled trial of olanzapine as maintenance therapy in patients with bipolar I disorder responding to acute treatment with olanzapine. Am J Psychiatry 2006, 163(2):247-256. 